\title{
Improving Mental Health Help-Seeking Amongst Male University Students: A Series of Gender-Sensitive Mental Health Pilot Interventions.
}

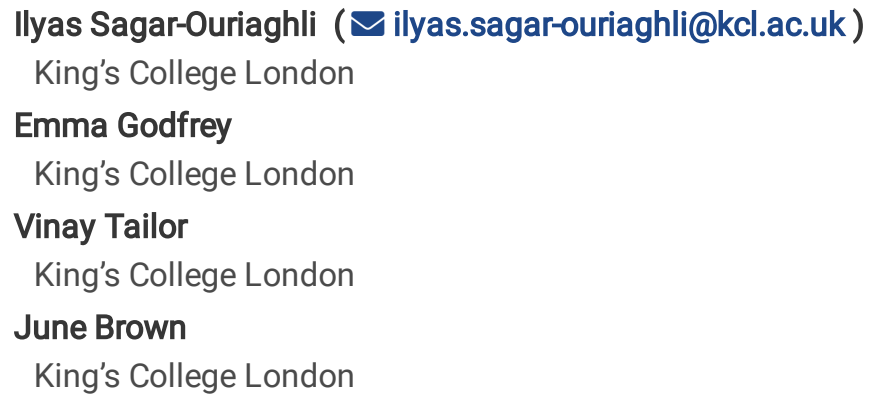

Research Article

Keywords: Help-seeking, Men, Interventions, Students, Mental Health, Pilot, Feasibility

Posted Date: September 1st, 2021

DOI: https://doi.org/10.21203/rs.3.rs-678030/v1

License: @ (i) This work is licensed under a Creative Commons Attribution 4.0 International License. Read Full License 


\section{Abstract}

\section{Background:}

Up to a third of students experience a common mental health condition which is associated with decreased academic functioning and an increased risk of dropping out. While the prevalence of common mental health difficulties is lower amongst male students, worryingly, they are twice as likely to die by suicide. The importance of developing interventions that are gender-sensitive for male students to improve their uptake of mental health initiatives has been recently emphasised. However, acceptable, feasible and effective methods for male students are unexplored. The current study conducted three gender-sensitive pilot interventions for male students to evaluate acceptability (including uptake), changes to help-seeking and mental health status.

\section{Methods:}

Three gender-sensitive interventions were delivered to 24 male students. The interventions consisted of: Intervention 1 - a formal mental health intervention targeting male students ("psycho-educational model"), Intervention 2 - a second formal intervention that adopted more gender-sensitive language and promoted positive masculine traits ("positive masculinity model"), and Intervention 3 an informal drop-in offering a social space for male students to receive general health information and connect with other students ("informal drop-in Man Cave model"). These were evaluated for acceptability (including uptake), attitudes to help-seeking and mental health outcomes.

\section{Results:}

In terms of acceptability, Intervention 3 - the informal drop-in (Man Cave) appeared better at engaging male students who have greater conformity to maladaptive masculine traits, more negative attitudes to help-seeking, higher levels of self-stigma, who were less likely to have used mental health support before and belonged to an ethnic minority. No significant changes to help-seeking attitudes, behaviours, or mental health status were observed across the interventions at feasibility stage. All interventions were deemed equally acceptable with minimal opportunity costs and perceived burden.

\section{Conclusions:}

These findings indicate differences in acceptability, particularly uptake, for male students who may be seen as more difficult to engage. Using informal strategies may help reach male students who would otherwise not engage with mental health support, familiarise them with the idea of help-seeking, and connect them with pre-existing mental health interventions. While no differences in outcomes measured were found in these small studies, more work needs to be carried out using larger samples to investigate the efficacy of informal interventions to engage male students.

\section{Background}

Mental health disorders are commonly reported amongst university students with prevalence rates ranging from $20-30 \%[1-3]$. Common mental health disorders such as depression and anxiety often contribute to greater drop-out rates and reduced academic functioning $[1,3,4,5]$. Although depression and anxiety are typically reported to occur more frequently amongst female students [2, 6], it is important to note that male students are more than twice as likely to die by suicide [7]. Indeed, higher suicide rates amongst male students has been observed since 2000 [7], and is consistent with older adults, where men are 2.35 times more likely to take their own life compared to women worldwide [8].

Higher suicide rates in male students can be partly explained by lower engagement with mental health services compared to female students $[4,9,10]$. This disparity in service use is a complex process with a multitude of barriers negatively influencing mental health service engagement for male students [11].Common barriers include, male students holding more negative attitudes to help-seeking $[12,13]$, having greater conformity to traditional masculine norms [14, 15], reporting both higher public- and self-stigma $[16,17]$, and poorer mental health literacy relative to their female counterparts $[13,18]$.

As conformity to masculine norms negatively influences help-seeking attitudes and behaviours amongst male students, it might act as a potential target area to elicit behaviour change and improve help-seeking $[14,15,19,20]$. However, recent work on positive masculinity suggests that general conformity to masculine norms may not be entirely detrimental. Conformity to specific traits such 
as emotional control, self-reliance, dominance, masculine toughness, and anti-femininity may well explain help-seeking reluctance [20-23]. On the other hand, masculine traits such as winning, masculine status, and in some instances, risk-taking can also be protective factors, helping to reduce the likelihood of mental health problems, as well as improving the chances of help-seeking occurring if problems do arise $[21,24,25]$.

Recent developments emphasise the importance of gender-sensitive interventions for male students [21, 26-29]. Indeed, male students may benefit from different techniques and approaches found to be effective for men of all ages when trying to improve help-seeking for mental health difficulties. These include the delivery of psychoeducation materials, reframing help-seeking to align with masculine norms, and the use of male role models to convey information. [30]. Other techniques found in male-specific interventions may include solution focused approaches, sensitively sign-posting services, and the use of lay language and humour [29-37].

By developing interventions that are more gender-sensitive for the needs of male university students, we aimed to achieve greater male engagement and uptake to mental health initiatives among them. In turn, this may help to improve mental health outcomes for male students and subsequently reduce their elevated risk for suicide. The current investigation sought to assess three gendersensitive mental health pilot interventions for male students by evaluating their differences in acceptability and feasibility. To be specific, the aims were:

1. To assess the overall acceptability of the three interventions.

2. To assess differences in acceptability scores between the three interventions.

3. To examine the types of male students who engage with the three interventions, regarding their help-seeking attitudes, selfstigma, conformity to masculine norms, mental health status, ethnicity, previous help-seeking, age, level of study, and degree faculty.

4. To assess the interventions' potential effectiveness for improving help-seeking attitudes, behaviours, and mental health status at post, 2-week, and 4-week follow up for all three interventions in order to power future studies.

\section{Methods}

\section{Design}

Descriptive statistics pertaining to self-stigma, conformity to masculine norms, mental health status, ethnicity, level of study, degree faculty, age, and previous help-seeking were used to analyse the types of students who engaged with the interventions. The acceptability of the three interventions was analysed to explore whether a particular intervention was more or less acceptable to male students. Lastly, a pre-post design was implemented across the three interventions to analyse changes in help-seeking attitudes, behaviours, and mental health status.

\section{Measures}

The measures utilised within this investigation comprised of acceptability (including uptake), conformity to masculine norms, selfstigma, help-seeking attitudes and behaviour, and mental health status. These are detailed below.

\section{Theoretical Framework of Acceptability Questionnaire.}

The Theoretical Framework of Acceptability Questionnaire (TFAQ) was used to evaluate the acceptability of the interventions [38]. The TFAQ contains 9 items evaluating eight distinct domains that relate to acceptability, including general acceptability, affective attitude, burden, ethicality, intervention coherence, opportunity costs, perceived effectiveness and self-efficacy [39]. Each domain includes one item except for perceived effectiveness where two items are included to capture the perceived effectiveness for helpseeking and mental health outcomes. All of the items are rated on a Likert scale ranging from 1 to 5 , where higher scores indicate better acceptability. One item also provides a textbox allowing for participants to provide qualitative feedback. Items 3 and 8 (burden and opportunity costs) are reversed coded, where lower scores represent greater acceptability.

As intervention 3 (Man Cave) was an informal drop-in, the uptake, total number of students attending, and the number of students consenting was recorded to further evaluate acceptability. 
The Conformity to Masculine Norms Inventory (CMNI-46) [40] and the Self-Stigma of Seeking-Help scale (SSOSH) [41] were completed at baseline as both conformity to masculine norms and self-stigma are barriers to help-seeking for male students [14-17, $19,20,42]$.

The CMNI-46 contains 46 items measuring the degree of conformity to nine traditional masculine norms including, winning, emotional control, primacy of work, risk-taking, violence, heterosexual self-presentation, playboy, self-reliance and power over women $[40,43]$. Items are rated on a 4-point Likert scale from strongly disagree ( 0 ) to strongly agree (3) and a score for each domain can be calculated by taking the mean score of the respective items for each domain. Furthermore, a mean score across all items is used to generate a total conformity to masculine norms score, whereby higher scores represent greater conformity to masculine norms [40, 43]. The CMNI-46 has good internal consistency $(a=0.78-0.89)$ [43].

The SSOSH scale includes 10 items rated on a 6-point Likert scale ranging from strongly disagree (0) to strongly agree (5). A total self-stigma score is obtained where higher scores indicate greater concern that seeking mental health support would negatively affect one's satisfaction with oneself, self-confidence, and overall self-worth. The SSOSH scale has strong internal consistency $(a=0.86-$ $0.90)$ and moderate test-retest reliability (0.72) [41].

Attitudes Towards Seeking Professional Psychological Help Scale and The Actual Help-Seeking Questionnaire.

To evaluate help-seeking attitudes and behaviours the Attitudes Towards Seeking Psychological Help-Scale - Short Form (ATSPPHSF) [44] and the Actual Help-Seeking Questionnaire (AHSQ) [45, 46] were used. The ATSPPH-SF contains 10 items rated on a 4-point Likert scale ranging from disagree ( 0 ) to agree (3). A total score for mental health help-seeking attitudes is obtained, whereby higher scores represent more favourable help-seeking attitudes. The ATSPPH-SF has moderate internal consistency $(a=0.77-0.84)$ and good test-retest reliability $(0.80)[44,47]$. Alongside help-seeking attitudes, the AHSQ contains 10 items measuring behavioural helpseeking (e.g. presenting to a service or speaking to friends and family) in the past 2-weeks. Similarly, the AHSQ has moderate internal consistency $(a=0.70-0.85)$ and good test-retest reliability $(0.86-0.92)[45]$.

Warwick-Edinburgh Mental Well-Being Scale.

Mental health status was measured via the Warwick-Edinburgh Mental Well-Being Scale (WEMWBS), a 14-item questionnaire containing positively phrased items measuring positive affect, psychological functioning, and personal relationships. Items are rated on a 5-point Likert scale ranging from none of the time (0) to all of the time (5). Scores are summed with higher scores representing greater overall well-being [48]. The WEMWBS has good internal consistency $(a=0.89)$ and test-retest reliability $(0.83)$ [48].

The ATSPPH-SF, AHSQ, and WEMWBS were completed at baseline for all interventions, post-intervention for interventions 1 and 2 and at both 2-week and 4-week follow up for all three interventions. Post intervention data for intervention 3 (Man-Cave) was not collected due to the informal, drop-in nature of the intervention, whereby the number of sessions and duration of participant intervention was not fixed.

\section{Interventions}

Ethical approval was granted for each intervention by the universities local Research Ethics Office. The content included within the three interventions was identified from a systematic review and focus groups conducted with male students [29, 30]. A theoretical framework specifically tailored towards male students outlines the development of the interventions [11]. The intervention's content was initially operationalised through the use of Behaviour Change Techniques (BCTs) $[49,50]$ stemming from the systematic review. These BCTs are listed within a taxonomy (BCTTV1) outlining a range of techniques that represent an intervention's active ingredients that promote behaviour change, in this case help-seeking [51]. Table 1 summarises the intervention content, BCTs utilised, and what this looked like in practice. By describing the development and active ingredients (i.e. BCTs) of each intervention in explicit detail, it enables other researchers or healthcare/education providers to replicate or build on the current findings. To further aid replication, a framework for developing interventions specifically for male students [11], the Template for Intervention Description and Replication (TIDieR) checklist (Additional file 1) and the Consolidated Standards of Reporting Trials (CONSORT) extension statement for reporting pilot or feasibility trials (Additional file 2) have been followed [52-54]. 
Additionally, focus group recommendations on how best to disseminate the interventions included: not to label them as a 'mental health' intervention, to provide an incentive for attending, to promote through student-led societies, and to deliver such initiatives during orientation week and exams [29].

Recruitment for each intervention lasted a duration of 4 weeks. This time frame was held consistent to highlight if one intervention was more acceptable than another. All three interventions were delivered face-to-face by a PhD student (ISO, male) with the support of a medical student (VT, male).

Table 1. Summary of the intervention content, BCTs utilised, and the delivery method across the three gender-sensitive interventions. 
Intervention
Content

Delivery of mental health information regarding depression, anxiety and alcohol misuse.

\section{BCT(s) \\ embedded \\ within the \\ intervention}

\section{1 .} Information about health consequences

5.3. Information about social \& environmental consequences

5.6.

Information

about

emotional consequences

Information on available mental health services, the treatment structure and its effectiveness.

\subsection{Social support (practical)}

5.1. Information about health consequences

\section{3.}

Information about social \& environmental consequences

Use of videos and photos of male celebrities who have experienced mental health help-seeking.

Emphasis placed on taking responsibility for your mental health.

\subsection{Social comparison}

9.1. Credible source

\subsection{Social support (practical)}

13.2 Framing/Reframing

Delivering a maleonly space whilst facilitating social support

\subsection{Social support (unspecified)}

Highlighting active problem solving/self-help techniques such as problemsolving, mindfulness, time management and action planning.

\subsection{Problem} solving

1.4. Action planning

11.2. Reduce negative emotions

Mental health selfassessment as part of a 'selfcheck' to evaluate one's current difficulties.

\section{Delivery method}

Group presentation for intervention 1 and 2 outlining what mental health is, stressors at university, symptoms associated with excessive low mood, excessive worry, and excessive alcohol use. Highlighting how many symptoms and when their duration is cause for concern. Case study examples/vignette's where students have to identify the symptoms. Intervention 3 included a leaflet about mental health symptoms, what they look like and when their duration is cause for concern.
Listing different types of support in both interventions 1 and 2 including: friends and family, online support, university services, and professional services in the NHS.

Emphasising that they have the choice to engage with any service they feel is appropriate. Presentation of a 'road map' regarding how long referrals, assessments, treatment duration, and the effectiveness of medication and cognitive behavioural therapy (CBT). Same information provided within a leaflet in intervention 3.
Group discussion on photographs of male celebrities from a range of professions who have openly discussed issues relating to mental health (e.g. Prince William and UK rapper Stormzy) and a short video from YouTube where male celebrities talk about their mental health struggles (Interventions 1 and 2 only).

\section{1} Monitoring of behaviour by others without feedback

2.2. Feedback on behaviour
Interventions 1 and 2 included a presentation highlighting that taking responsibility and finding appropriate support is a positive. Support can extend to friends, family, and professional support. Group discussion on why men find it difficult to ask for help. Intervention 2 and 3 labelled as 'improving psychological strength for men' and 'man-cave' to align with male stereotypes.

Group based interventions specifically for male-students. Games console activity after interventions 1 and 2 as part of the honorarium given. Intervention 3 provided an informal drop in space to meet other male students by providing a series of social activities (games console, board games, arts and crafts, and table tennis).

Interventions 1 and 2 includes information and practice activities for relaxation techniques (5-minute YouTube activity on mindfulness), solving a novel problem (e.g. how to make $£ 1$ million in 6 months), time management (a case study/vignette on how to improve a student's poor time management), and action planning where student's identify 3 key problems and 3 potential solutions that can be completed in the next month. Intervention 2 had additional information about behavioural activation, how to identify negative cycles and patterns of behaviour and how to change them as well as setting and monitoring goals.

Completion of the Warwick-Edinburgh Menta Well-Being Scale (WEMWBS) as a 'selfcheck' exercise for interventions 1 and 2. Repeated again in session 2, with the addition of calculating total scores and what 'healthy' or average scores (i.e. 50) look like - if substantially lower participants were reminded of the content addressed such as finding support and self-help techniques. Intervention 3 included the WEMWBS as a 'self-check' within a leaflet. 
2.3. Self-

monitoring of

behaviour

\section{Intervention 1: Men-Tality}

Prior to recruitment, a survey was sent to 20 male students to identify a title for a mental health intervention. The preferred name for the intervention was 'Men-Tality: A Mental Health Workshop for Male Students'. The intervention was promoted during orientation week at the university welcome fair where university societies can show-case extra-curricular activities [29]. Additionally, posters and the fortnightly university e-mail circular that is sent to all students was used to promote the intervention.

Intervention 1 was a psycho-educational intervention designed to improve knowledge of mental health problems and what they could do to help themselves as well as what help they could seek. It was delivered in a room located in the student union and was divided into two 2-hour group sessions. In session 1, information on mental health symptoms (depression, anxiety, and alcohol misuse) and how to recognise them, available mental health services, treatment structure, treatment effectiveness, videos/photos of male celebrities who have experienced mental health difficulties to frame help-seeking within a masculine narrative, and greater emphasis placed on taking responsibility for your mental health were addressed (Table 1). In the following week, session 2, a video of male celebrities discussing mental health difficulties and help-seeking was shown before exploring a range of skills including problemsolving, mindfulness, time management, and action planning. Lastly, a mental health self-assessment (i.e. WEMWBS) was completed individually for students to do a 'self-check' within the session. Responses were used to privately evaluate one's current difficulties and participants were reminded of the available services and self-management techniques that were addressed in sessions 1 and 2 (Table 1).

\section{Intervention 2: Psychological Strength for Men}

Intervention 2 was titled 'Improving Psychological Strength for Men' to provide a more 'positive masculine' image, enabling male students to engage with a mental health intervention without contradicting their perceived sense of self/masculinity (i.e. 'being weak'). The aim and content embedded within intervention 2 differed from intervention 1 as it focused more on problem-solving and solution focused techniques - discussing them in the first session, whilst also placing greater emphasis on positive masculine stereotypes (e.g. responsibility and psychological strength) (Table 1). As before, mental health labels were deliberately avoided to help engage more male students [29]. The phrasing of 'psychological' was chosen to avoid mental health related terms, and information relating to depression, anxiety, and alcohol misuse were labelled as 'low mood', 'worries/stress' and 'excessive drinking', respectively. Posters and the fortnightly e-mail circular were used to promote the intervention to all students.

Intervention 2 was also divided into two 2-hour group sessions. Session 1 focused on skills such as behavioural-activation, actionplanning, mindfulness, goal setting and monitoring, problem-solving, and time management techniques. The following week, session 2 emphasised one's responsibility to look after their mental health before providing information around available mental health services, identifying mental health symptoms, treatment structure, and treatment effectiveness. Lastly, mental health selfassessments (i.e. WEMBWS) were completed to obtain personal feedback about their current mental health status (Table 1).

\section{Intervention 3: Man Cave}

Intervention 3 was designed to be informal and offer a group drop-in for male students. It was based on previous focus group results, indicating that male students also have a preference for informal and fun settings [29]. Intervention 3 was titled 'Man Cave' to emphasise a male-only group and was hosted on the ground floor within the student union in close proximity to the student café. This ensured a more opportunistic setting, unlike interventions 1 and 2 where pre-registration/sign up was required. As before, intervention 3 was advertised via posters and across the fortnightly e-mail circular to all students. Students were invited to sign up once they entered.

Intervention content was delivered through leaflets that were placed on an information desk within the room. There were two researchers (ISO and VT) available to answer any questions they might have. Students were free to discretely collect leaflets that were relevant to them without prompt or discussion with anyone. Specially adapted leaflets containing information about available mental health services, mental health symptoms, and a self-assessment scale (i.e. WEMBWS) were provided. Additional leaflets addressing physical health, local doctor's surgeries, smoking cessation, and university gyms were provided (Table 1). Various social

Page $7 / 23$ 
activities such as board games, video gaming, table tennis, and snacks were stationed around the room to shift the focus away from mental health with the intention to be more inviting to male-students (Table 1). Drop-in sessions ran weekly for 4 hours for a series of 4 weeks. Students were free to attend for any time period and attend as many sessions as they liked.

\section{Results}

\section{Participants}

Across the three pilot interventions, 24 male students were recruited. For participants to be eligible to participate they had to identify as male as well as be a student (undergraduate or postgraduate). A specific sample size was not pre-determined as the current pilot investigation sought to explore how many students would engage as a means to test the acceptability and feasibility of the interventions. 126 students expressed interest in intervention 1 (Men-Tality) and provided contact details to a member of the research team at the welcome fair. An additional 23 students responded to the poster/e-mail invitation. Of the 149 male students expressing interest in intervention 1, 9 students attended and completed the intervention. Due to logistical restrictions and to prevent students from engaging in both interventions simultaneously, interventions 2 (Psychological Strength) and 3 (Man Cave) were promoted later on within the academic year. Subsequently, they were not advertised during welcome fair. 22 students expressed interest in intervention 2, with 6 attending the intervention where all completed 4-week follow. For intervention 3, 15 students expressed interest, resulting in 9 consenting to take part and 3 completing 4-week follow up. Within intervention 3, only one student completed both 2week and 4-week follow up. A summary of students agreeing to take part, uptake, and completion rates is depicted in Fig. 1. Demographic information of the 24 participants split by each intervention is outlined in Table 2. 
Table 2

Summary of participants demographics split by intervention.

\begin{tabular}{|c|c|c|c|c|}
\hline & $\begin{array}{l}\text { Intervention } 1 \\
\text { (Men-Tality) }\end{array}$ & $\begin{array}{l}\text { Intervention } 2 \\
\text { (Psych Strength) }\end{array}$ & $\begin{array}{l}\text { Intervention } 3 \\
\text { (Man Cave) }\end{array}$ & Total \\
\hline$n(\%$ male $)$ & $9(100 \%)$ & $6(100 \%)$ & $9(100 \%)$ & $24(100 \%)$ \\
\hline Mean Age in years (SD) & $25.44(8.71)$ & $25.50(4.51)$ & $22.11(4.81)$ & $24.21(6.45)$ \\
\hline \multicolumn{5}{|l|}{ Ethnicity } \\
\hline Other White Background & $4(44 \%)$ & $4(66 \%)$ & $0(0 \%)$ & $8(34 \%)$ \\
\hline Pakistani & $0(0 \%)$ & $1(17 \%)$ & $4(44 \%)$ & $5(22 \%)$ \\
\hline Black African & $0(0 \%)$ & $0(0 \%)$ & $2(22 \%)$ & $2(8 \%)$ \\
\hline White British & $1(11 \%)$ & $0(0 \%)$ & $1(11 \%)$ & $2(8 \%)$ \\
\hline Chinese & $1(11 \%)$ & $0(0 \%)$ & $0(0 \%)$ & $1(4 \%)$ \\
\hline Indian & $1(11 \%)$ & $0(0 \%)$ & $0(0 \%)$ & $1(4 \%)$ \\
\hline Bangladeshi & $0(0 \%)$ & $0(0 \%)$ & $1(11 \%)$ & $1(4 \%)$ \\
\hline Mixed White and Black Caribbean & $0(0 \%)$ & $1(17 \%)$ & $0(0 \%)$ & $1(4 \%)$ \\
\hline Other Asian Background & $1(11 \%)$ & $0(0 \%)$ & $0(0 \%)$ & $1(4 \%)$ \\
\hline Any other background & $1(11 \%)$ & $0(0 \%)$ & $1(11 \%)$ & $2(8 \%)$ \\
\hline \multicolumn{5}{|l|}{ Degree Faculty } \\
\hline Natural \& Mathematical Sciences & $3(33 \%)$ & $2(33 \%)$ & $8(89 \%)$ & $13(55 \%)$ \\
\hline Social Sciences \& Public Policy & $2(22 \%)$ & $2(33 \%)$ & $0(0 \%)$ & $4(16 \%)$ \\
\hline Arts \& Humanities & $1(11 \%)$ & $1(17 \%)$ & $1(11 \%)$ & $3(13 \%)$ \\
\hline Psychiatry, Psychology \& Neuroscience & $2(22 \%)$ & $0(0 \%)$ & $0(0 \%)$ & $2(8 \%)$ \\
\hline Life Science \& Medicine & $0(0 \%)$ & $1(17 \%)$ & $0(0 \%)$ & $1(4 \%)$ \\
\hline School of Law & $1(11 \%)$ & $0(0 \%)$ & $0(0 \%)$ & $1(4 \%)$ \\
\hline \multicolumn{5}{|l|}{ Level of Study } \\
\hline Undergraduate & $4(44 \%)$ & $1(17 \%)$ & $7(78 \%)$ & $12(50 \%)$ \\
\hline Postgraduate (Masters or PhD) & $5(56 \%)$ & $5(83 \%)$ & $2(22 \%)$ & $12(50 \%)$ \\
\hline \multicolumn{5}{|c|}{ Has previously sought help for mental health } \\
\hline Yes & $4(44 \%)$ & $5(83 \%)$ & $2(22 \%)$ & $11(46 \%)$ \\
\hline No & $4(44 \%)$ & $0(0 \%)$ & $6(67 \%)$ & $10(41 \%)$ \\
\hline Prefer not to say & $1(11 \%)$ & 1 (17\%) & $1(11 \%)$ & $3(13 \%)$ \\
\hline
\end{tabular}

Aim 1: To assess the overall acceptability for all three interventions.

Mean (SD) scores for all acceptability domains (general acceptability, affective attitude, burden, ethicality, intervention coherence, opportunity costs, perceived effectiveness and self-efficacy) are summarised in Table 4. All three interventions were rated favourably regarding their overall acceptability with $76 \%(n=13)$ rating the intervention as 'acceptable' and $24 \%(n=4)$ rating the intervention as 'completely acceptable'. Similarly, $82 \%(n=14)$ of participants either 'liked' or 'strongly liked' their respective intervention, whilst only $18 \%(n=3)$ had 'no opinion'. When asked how much the intervention aligned with their beliefs about mental health and help-seeking, (ethicality) $88 \%(n=15)$ were in 'agreement' or 'strong agreement', $6 \%(n=1)$ had 'no opinion', whilst $6 \%(n=1)$ 'disagreed'.

Participants were also asked whether the intervention improved their overall mental health/well-being and their attitudes towards 
seeking help (perceived effectiveness). For overall mental health/well-being, 47\% ( $n=8)$ 'agreed', 35\% $(n=6)$ had 'no opinion' and 18\% $(n=3)$ 'disagreed'. Similarly, for attitudes towards seeking help, 65\% $(n=11)$ either 'agreed' or 'strongly agreed' whilst $35 \%(n=6)$ had 'no opinion'. When asked whether it was clear how engaging in the intervention helped to manage their mental health (intervention coherence), $76 \%(n=13)$ 'agreed' or 'strongly agreed' that it was clear and $24 \%(n=4)$ had 'no opinion'. Additionally, two negatively phrased items were included to identify how much effort it took to engage (burden) and how much engaging interfered with other priorities (opportunity costs). $65 \%(n=11)$ felt engaging took 'very little effort' or 'no effort at all', $18 \%(n=3)$ had 'no opinion', $12 \%$ ( $n$ $=2)$ took 'a lot of effort' and $6 \%(n=1)$ required a 'huge effort'. When asked whether the intervention interfered with their other priorities, $76 \%(n=13)$ 'disagreed' or 'strongly disagreed' and $24 \%(n=4)$ had 'no opinion'. Lastly, participants were asked how confident they would feel about engaging with the intervention again (self-efficacy), $71 \%(n=12)$ felt 'confident' or 'very confident' about engaging again, whilst $29 \%(n=5)$ had 'no opinion'. The final question included within the TFAQ captures general feedback obtained through a written text box. 12 of the 17 participants completing the TFAQ provided verbal feedback (Table 3).

Table 3

Verbal feedback obtained from the TFAQ.

\begin{tabular}{|c|c|}
\hline Intervention & Comment \\
\hline \multirow{7}{*}{$\begin{array}{l}\text { Intervention 1: Men- } \\
\text { Tality }\end{array}$} & "I only hope that more people would participate in this, as mental well-being is often neglected" (1) \\
\hline & "Good overview of mental health issues and ways to cope and where to get help" (1) \\
\hline & "I found it enjoyable, FIFA is a great way to get people together" (1) \\
\hline & $\begin{array}{l}\text { "Although I can see how some of the strategies discussed may help some people, in my case they seem } \\
\text { unlikely to work" (1) }\end{array}$ \\
\hline & "Was useful, learnt new techniques, forced me to reflect more on my own wellbeing" (1) \\
\hline & $\begin{array}{l}\text { "Would have been useful to go through ways of 'nudging' us to do beneficial activities for mental health } \\
\text { so they become a habit" (1) }\end{array}$ \\
\hline & $\begin{array}{l}\text { "To take care of yourself is taking care of your mental health. This is the first and most important step to } \\
\text { begin with if you want to improve" (1) }\end{array}$ \\
\hline \multirow{2}{*}{$\begin{array}{l}\text { Intervention 2: } \\
\text { Psychological } \\
\text { strength for men }\end{array}$} & "Not sure that $2 \times 2$ hour workshop brings big changes, but the atmosphere was good" (2) \\
\hline & "Very good overall” (2) \\
\hline \multirow{3}{*}{$\begin{array}{l}\text { Intervention 3: } \\
\text { Man Cave }\end{array}$} & $\begin{array}{l}\text { "I had only come for one session, so perhaps I most likely wasn't able to benefit too much as far as } \\
\text { mental health is concerned but I certainly did leave happier after my session" (3) }\end{array}$ \\
\hline & $\begin{array}{l}\text { "I didn't know how I could have engaged more beyond my lengthy discussion with one of the organisers, } \\
\text { apart from that I was too tentative to get involved" (3) }\end{array}$ \\
\hline & $\begin{array}{l}\text { "I have no strong opinions. I feel it may be useful for some more vulnerable guys, but I believe men } \\
\text { should be able to deal with their problems themselves and these kinds of things don't appeal to most } \\
\text { men" (3) }\end{array}$ \\
\hline
\end{tabular}

Aim 2: To assess differences in acceptability scores between the interventions.

As indicated by a series of one-way ANOVA's, no significant differences were observed for all the domains on the TFAQ (overall acceptability, affective attitude, burden, ethicality, intervention coherence, opportunity costs, perceived effectiveness and self-efficacy) (Table 4). 
Table 4

Summary of Means, SD and One-Way ANOVA for all interventions scores for acceptability.

\begin{tabular}{|c|c|c|c|c|c|c|c|}
\hline \multirow[b]{2}{*}{ TFAQ Domain } & \multicolumn{3}{|l|}{ Mean (SD) } & \multicolumn{4}{|c|}{$\begin{array}{l}\text { One-Way ANOVA between the three } \\
\text { pilot interventions }\end{array}$} \\
\hline & $\begin{array}{l}\text { Intervention } 1 \\
\text { (Men-Tality) }\end{array}$ & $\begin{array}{l}\text { Intervention } 2 \\
\text { (Psych Strength) }\end{array}$ & $\begin{array}{l}\text { Intervention } 3 \\
\text { (Man Cave) }\end{array}$ & $F$ & $\mathrm{df}$ & Error & $p$ \\
\hline Acceptability & $4.78(0.44)$ & $4.75(0.50)$ & $4.75(0.50)$ & 0.01 & 2 & 14 & 0.993 \\
\hline Affective Attitude & $4.11(0.78)$ & $4.50(0.58)$ & $4.25(0.96)$ & 0.34 & 2 & 14 & 0.717 \\
\hline Burden ${ }^{\mathrm{R}}$ & $2.11(1.17)$ & $2.25(0.96)$ & $3.25(0.96)$ & 1.59 & 2 & 14 & 0.238 \\
\hline Ethicality & $4.33(0.71)$ & $4.25(0.50)$ & $3.50(1.00)$ & 1.82 & 2 & 14 & 0.198 \\
\hline $\begin{array}{l}\text { Intervention Coherence } \\
\text { (help-seeking) }\end{array}$ & $4.22(0.67)$ & $3.75(0.50)$ & $3.75(0.96)$ & 0.94 & 2 & 14 & 0.415 \\
\hline Opportunity Costs ${ }^{R}$ & $2.00(0.71)$ & $1.75(0.96)$ & $1.75(0.96)$ & 0.20 & 2 & 14 & 0.825 \\
\hline $\begin{array}{l}\text { Perceived Effectiveness } \\
\text { (help-seeking) }\end{array}$ & $4.00(0.71)$ & $4.00(0.82)$ & $3.25(0.50)$ & 1.78 & 2 & 14 & 0.204 \\
\hline $\begin{array}{l}\text { Perceived Effectiveness } \\
\text { (mental health) }\end{array}$ & $3.44(0.73)$ & $3.00(1.15)$ & $3.25(0.50)$ & 0.44 & 2 & 14 & 0.656 \\
\hline Self-Efficacy & $3.89(0.60)$ & $3.75(0.96)$ & $4.00(0.82)$ & 0.12 & 2 & 14 & 0.892 \\
\hline \multicolumn{8}{|c|}{${ }^{\mathrm{R}}$ Items are reverse coded, lower scores indicate better acceptability. } \\
\hline$* p<0.05$ & & & & & & & \\
\hline
\end{tabular}

Aim 3: To examine the types of male students who engage with the interventions regarding their help-seeking attitudes, self-stigma, conformity to masculine norms, mental health status, ethnicity, previous help-seeking, age, level of study, and degree faculty.

\section{Baseline Help-Seeking Attitudes}

Across the three interventions, scores for help-seeking attitudes as measured by the ATSPPH-SF were significantly different at baseline (Table 5). A Bonferroni post-hoc test revealed that help-seeking attitudes were significantly lower for intervention 3 when compared to intervention $1(p=0.006)$. No significant differences were observed between intervention 1 and $2(p=0.892)$, or between intervention 2 and $3(p=0.147)$.

When comparing help-seeking attitudes at baseline to male student norms in previous research [47], participants in intervention 1 had significantly more positive help-seeking attitudes, $t(8)=3.917, \mathrm{p}=0.004,95 \% \mathrm{Cl}(2.28$ to 8.81$), d=1.13$. No significant differences for help-seeking attitudes were observed for intervention $2, t(5)=2.311, \mathrm{p}=.069,95 \% \mathrm{Cl}(-0.35$ to 6.55$), d=0.69$, or intervention $3, t(8)=$ $1.013, \mathrm{p}=.341,95 \% \mathrm{Cl}(-5.05$ to 2.14$), d=0.31$, when compared to male student norms [47].

\section{Baseline Self-Stigma}

Upon visual inspection, baseline self-stigma appeared lower for both interventions 1 and 2 when compared to intervention 3. However, this difference was not significant (Table 5). However, when compared to male student norms outlined in previous research, a one-sample t-test showed that baseline self-stigma for intervention 1 was significantly lower than male student norms [41], $t(8)=$ $2.71, p=0.027,95 \% \mathrm{Cl}(-8.41$ to -0.68$), d=0.70$. Similarly, baseline self-stigma of participants for intervention 2 was significantly lower when compared to male student norms, $t(5)=2.57, p=0.050,95 \% \mathrm{Cl}(-13.52$ to -0.01$), d=0.95$. However, for intervention 3 , baseline self-stigma was not significantly different to the male student norms, $t(7)=0.37, p=0.726,95 \% \mathrm{Cl}(-8.24$ to 6.04$), d=0.13$.

\section{Baseline Conformity to Masculine Norms}

Across the three interventions, only the domains of winning and heterosexual self-preservation revealed significant differences (Table 5). Employing the Bonferroni post-hoc test, winning was significantly higher for intervention 2 when compared to intervention 1 
$(p=0.013)$. However, there were no significant differences for winning between interventions 1 and $3(p=1.00)$, or between intervention 2 and $3(p=0.067)$.

Similarly, the Bonferroni post-hoc test for heterosexual self-preservation revealed this to be significantly higher for intervention 3 when compared to intervention $1(p=0.019)$. There were no significant differences for hetero-sexual self-preservation between interventions 1 and $2(p=1.00)$, or between interventions 2 and $3(p=0.223)$.

Furthermore, when comparing conformity to masculine norms with male student norms as highlighted in previous research [43], those attending intervention 1 scored significantly lower on total conformity to masculine norms, $t(8)=5.102, p=0.001,95 \% \mathrm{Cl}$ $(-0.581$ to -0.219$), d=1.67$, power over women, $t(8)=4.728, \mathrm{p}=0.001,95 \% \mathrm{Cl}(-0.972$ to -0.335$), d=1.31$, and heterosexual selfpreservation $t(8)=6.340, \mathrm{p}<0.001,95 \% \mathrm{Cl}(-1.445$ to -0.674$), d=1.81$. No significant differences were observed for emotional control, winning, playboy, violence, self-reliance, risk taking, and primacy of work when comparing intervention 1 to male student norms.

For those attending intervention 2, scores for heterosexual self-preservation were significantly lower compared to male student norms, $t(5)=2.933, p=0.033,95 \% \mathrm{Cl}(-1.395$ to -0.092$), d=1.16$. All other domains of, total conformity to masculine norms, emotional control, winning, playboy, violence, self-reliance, risk-taking, power over women, and primacy of work did not differ significantly to male student norms. Lastly, participants attending intervention 3 did not have any significant differences across all domains when compared to male student norms.

\section{Baseline Mental Health Status}

As measured by the WEMWBS, mental health status did not differ significantly at baseline between the three interventions (Table 5). Mental health status at baseline for intervention 1 did not differ significantly from male student's norms as highlighted in previous research [48], $t(8)=0.509, \mathrm{p}=0.624,95 \% \mathrm{Cl}(-4.60$ to 7.21$), d=0.17$. This was also observed for intervention $2, t(5)=1.130, p=0.310$, $95 \% \mathrm{Cl}(-20.11$ to 7.83$), d=0.56$, and intervention $3, t(8)=0.551, \mathrm{p}=0.597,95 \% \mathrm{Cl}(-11.67$ to 7.17$), d=0.21$.

\section{Ethnicity, Previous Help-Seeking, Age, Level of Study, and Degree Faculty at Baseline}

Furthermore, of the participants engaging within the three interventions, significant differences were observed for ethnicity, whereby intervention 3 engaged more ethnic minorities: Fisher's Exact, $p=0.021$, Cramer's $V=0.707$ and for those who have previously sought help for mental health compared to those who have not: Fisher's Exact, $p=0.038$, Cramer's $V=0.58$. No significant differences were observed for age as confirmed by a one-way ANOVA: $F(2,21)=0.745, p=0.487$. Lastly, Fisher's exact test revealed no significant differences between the interventions for level of study $(p=0.089)$ or degree faculty $(p=0.106)$. 
Table 5

Summary of Means, SD and One-Way ANOVA for all intervention's baseline scores for help-seeking attitudes, mental health status, self-stigma, and conformity to masculine norms.

\begin{tabular}{|c|c|c|c|c|c|c|c|c|}
\hline \multirow[t]{3}{*}{ Scale } & \multicolumn{4}{|l|}{ Mean $(S D)$} & \multicolumn{4}{|c|}{$\begin{array}{l}\text { One-Way ANOVA between the } \\
\text { three pilot interventions }\end{array}$} \\
\hline & $\begin{array}{l}\text { Intervention } \\
1\end{array}$ & $\begin{array}{l}\text { Intervention } \\
2\end{array}$ & $\begin{array}{l}\text { Intervention } \\
3\end{array}$ & \multirow{2}{*}{$\begin{array}{l}\text { Male } \\
\text { student } \\
\text { norms }\end{array}$} & \multirow[t]{2}{*}{$F$} & \multirow[t]{2}{*}{ df } & \multirow[t]{2}{*}{ Error } & \multirow[t]{2}{*}{$p$} \\
\hline & $\begin{array}{l}\text { (Men- } \\
\text { Tality) }\end{array}$ & $\begin{array}{l}\text { (Psych } \\
\text { Strength) }\end{array}$ & (Man Cave) & & & & & \\
\hline $\begin{array}{l}\text { Baseline Help-Seeking Attitudes } \\
\text { (ATSPPHS-SF) }\end{array}$ & $\begin{array}{l}21.44 \\
(4.25)\end{array}$ & $\begin{array}{l}19.00 \\
(3.29)\end{array}$ & $\begin{array}{l}14.22 \\
(5.29)\end{array}$ & $\begin{array}{l}15.90 \\
(5.44)\end{array}$ & 6.39 & 2 & 21 & $0.007 *$ \\
\hline $\begin{array}{l}\text { Baseline Mental Health Status } \\
\text { (WEMWBS) }\end{array}$ & $\begin{array}{l}50.44 \\
(7.68)\end{array}$ & $\begin{array}{l}43.00 \\
(13.31)\end{array}$ & $\begin{array}{l}46.89 \\
(13.07)\end{array}$ & $\begin{array}{l}49.14 \\
(7.87)\end{array}$ & 0.83 & 2 & 21 & 0.451 \\
\hline Baseline Self-Stigma (SSOSH) & $\begin{array}{l}22.56 \\
(5.03)\end{array}$ & $\begin{array}{l}20.33 \\
(6.44)\end{array}$ & $\begin{array}{l}26.00 \\
(8.96)\end{array}$ & $\begin{array}{l}27.10 \\
(7.70)\end{array}$ & 1.26 & 2 & 20 & 0.306 \\
\hline \multicolumn{9}{|c|}{ Baseline Conformity to Masculine Norms (CMNI-46) } \\
\hline Total & $1.11(0.23)$ & $1.36(0.34)$ & $1.42(0.44)$ & $1.51(0.25)$ & 2.07 & 2 & 21 & 0.152 \\
\hline Emotional Control & $1.15(0.60)$ & $0.97(0.87)$ & $1.46(0.66)$ & $1.45(0.54)$ & 1.01 & 2 & 21 & 0.381 \\
\hline Winning & $1.37(0.43)$ & $2.14(0.62)$ & $1.54(0.38)$ & $1.66(0.45)$ & 5.33 & 2 & 21 & $0.013^{*}$ \\
\hline Playboy & $1.08(0.43)$ & $1.29(0.75)$ & $1.44(0.68)$ & $1.28(0.65)$ & 0.78 & 2 & 21 & 0.470 \\
\hline Violence & $1.43(0.55)$ & $1.61(0.64)$ & $1.41(0.80)$ & $1.84(0.49)$ & 0.20 & 2 & 21 & 0.823 \\
\hline Self-Reliance & $1.04(0.44)$ & $1.43(0.94)$ & $1.37(0.88)$ & $1.33(0.49)$ & 0.65 & 2 & 21 & 0.532 \\
\hline Risk Taking & $1.36(0.53)$ & $1.27(0.84)$ & $1.49(0.41)$ & $1.45(0.46)$ & 0.28 & 2 & 21 & 0.761 \\
\hline Power Over Women & $0.42(0.41)$ & $0.63(0.44)$ & $0.89(1.11)$ & $1.07(0.57)$ & 0.75 & 2 & 21 & 0.486 \\
\hline Primacy of Work & $1.22(0.67)$ & $1.63(0.74)$ & $1.20(0.36)$ & $1.36(0.54)$ & 1.08 & 2 & 21 & 0.357 \\
\hline Heterosexual Self-Preservation & $0.74(0.50)$ & $1.06(0.62)$ & $1.76(0.88)$ & $1.80(0.66)$ & 4.79 & 2 & 21 & $0.007 *$ \\
\hline \multicolumn{9}{|l|}{${ }^{*} p<0.05$} \\
\hline $\begin{array}{l}\text { Key: ATSPPHS-SF, Attitudes } \\
\text { Mental Well-Being Scale; CM }\end{array}$ & Seeking $F$ & ional & 1 & e - Sho & $n \cdot d$ & & laru & \\
\hline
\end{tabular}

Aim 4: To assess the interventions' potential effectiveness for improving help-seeking attitudes, behaviours, and mental health status at post, 2-week, and 4-week follow up for all three interventions in order to power future studies.

\section{Post-Intervention Changes to Help-Seeking Attitudes \& Behaviours}

Certainly, the primary aim for pilot studies should be to assess feasibility and acceptability [55]. Nonetheless, despite the small sample sizes, an exploratory analysis was conducted to examine changes to help-seeking attitudes and behaviours at follow up. For interventions 1 and 2, no significant changes in help-seeking attitudes were observed at post-intervention, 2-week follow up, or 4-week follow up when compared to baseline (Table 7). Similarly, no significant changes to help-seeking attitudes were observed in intervention 3 for 2-week follow up or 4-week follow-up when compared to baseline (Table 7).

With regards to help-seeking behaviours occurring in the past 2 weeks captured by the AHSQ, more than half (50\%) of participants completing the questionnaire sought help at any time point (i.e., baseline, post intervention, 2-week follow up, 4-week follow up) from at least 1 source (Table 6). Only a positive increase in students seeking help in the past two weeks was observed for intervention 1 at post follow up $(+11 \%)($ Table 6$)$. 
Table 6

Frequency and percentages of where participants sought help in the last 2 weeks at baseline, post, 2-week follow up and 4-week follow up for all interventions.

\begin{tabular}{|c|c|c|c|c|c|c|c|c|c|c|c|c|}
\hline \multirow[b]{2}{*}{ Timepoint } & \multicolumn{4}{|c|}{$\begin{array}{l}\text { Intervention } 1 \\
\text { (Men-Tality) }\end{array}$} & \multicolumn{4}{|c|}{$\begin{array}{l}\text { Intervention } 2 \\
\text { (Psych Strength) }\end{array}$} & \multicolumn{4}{|c|}{$\begin{array}{l}\text { Intervention } 3 \\
\text { (Man Cave) }\end{array}$} \\
\hline & Baseline & Post & 2WFU & 4WFU & Baseline & Post & $2 W F U$ & 4WFU & Baseline & Post & $2 W F U$ & $4 \mathrm{WFU}$ \\
\hline n total & 9 & 9 & 9 & 9 & 6 & 3 & 6 & 6 & 9 & 0 & 2 & 3 \\
\hline Partner & $22 \%(2)$ & $\begin{array}{l}22 \% \\
(2)\end{array}$ & $\begin{array}{l}22 \% \\
(2)\end{array}$ & $\begin{array}{l}11 \% \\
(1)\end{array}$ & $50 \%(3)$ & $\begin{array}{l}33 \% \\
(1)\end{array}$ & $\begin{array}{l}67 \% \\
(4)\end{array}$ & $\begin{array}{l}67 \% \\
(4)\end{array}$ & $11 \%(1)$ & - & $\begin{array}{l}0 \% \\
(0)\end{array}$ & $\begin{array}{l}0 \% \\
(0)\end{array}$ \\
\hline Friend & $44 \%(4)$ & $\begin{array}{l}67 \% \\
(6)\end{array}$ & $\begin{array}{l}67 \% \\
(6)\end{array}$ & $\begin{array}{l}44 \% \\
(4)\end{array}$ & $\begin{array}{l}100 \% \\
(6)\end{array}$ & $\begin{array}{l}67 \% \\
(2)\end{array}$ & $\begin{array}{l}83 \% \\
(5)\end{array}$ & $\begin{array}{l}83 \% \\
\text { (5) }\end{array}$ & $33 \%(1)$ & - & $\begin{array}{l}100 \% \\
(2)\end{array}$ & $\begin{array}{l}67 \% \\
(2)\end{array}$ \\
\hline Parent & $22 \%(2)$ & $\begin{array}{l}22 \% \\
(2)\end{array}$ & $\begin{array}{l}33 \% \\
(3)\end{array}$ & $\begin{array}{l}22 \% \\
(2)\end{array}$ & $67 \%(4)$ & $\begin{array}{l}33 \% \\
(1)\end{array}$ & $\begin{array}{l}50 \% \\
(3)\end{array}$ & $\begin{array}{l}67 \% \\
(4)\end{array}$ & $44 \%(4)$ & - & $\begin{array}{l}100 \% \\
(2)\end{array}$ & $\begin{array}{l}0 \% \\
(0)\end{array}$ \\
\hline $\begin{array}{l}\text { Other } \\
\text { Relative }\end{array}$ & $11 \%(1)$ & $\begin{array}{l}11 \% \\
(1)\end{array}$ & $\begin{array}{l}11 \% \\
(1)\end{array}$ & $\begin{array}{l}11 \% \\
(1)\end{array}$ & $33 \%(2)$ & $\begin{array}{l}0 \% \\
(0)\end{array}$ & $\begin{array}{l}67 \% \\
(4)\end{array}$ & $\begin{array}{l}33 \% \\
(2)\end{array}$ & $0 \%(0)$ & - & $\begin{array}{l}0 \% \\
(0)\end{array}$ & $\begin{array}{l}33 \% \\
(1)\end{array}$ \\
\hline $\begin{array}{l}\text { Mental } \\
\text { Health } \\
\text { Professional }\end{array}$ & $0 \%(0)$ & $\begin{array}{l}0 \% \\
(0)\end{array}$ & $\begin{array}{l}0 \% \\
(0)\end{array}$ & $\begin{array}{l}0 \% \\
(0)\end{array}$ & $17 \%(1)$ & $\begin{array}{l}33 \% \\
(1)\end{array}$ & $\begin{array}{l}0 \% \\
(0)\end{array}$ & $\begin{array}{l}33 \% \\
(2)\end{array}$ & $11 \%(1)$ & - & $\begin{array}{l}0 \% \\
(0)\end{array}$ & $\begin{array}{l}0 \% \\
(0)\end{array}$ \\
\hline $\begin{array}{l}\text { Phone help } \\
\text { line }\end{array}$ & $0 \%(0)$ & $\begin{array}{l}0 \% \\
(0)\end{array}$ & $\begin{array}{l}0 \% \\
(0)\end{array}$ & $\begin{array}{l}0 \% \\
(0)\end{array}$ & $0 \%(0)$ & $\begin{array}{l}0 \% \\
(0)\end{array}$ & $\begin{array}{l}0 \% \\
(0)\end{array}$ & $\begin{array}{l}0 \% \\
(0)\end{array}$ & $0 \%(0)$ & - & $\begin{array}{l}0 \% \\
(0)\end{array}$ & $\begin{array}{l}0 \% \\
(0)\end{array}$ \\
\hline Doctor / GP & $0 \%(0)$ & $\begin{array}{l}0 \% \\
(0)\end{array}$ & $\begin{array}{l}0 \% \\
(0)\end{array}$ & $\begin{array}{l}0 \% \\
(0)\end{array}$ & $0 \%(0)$ & $\begin{array}{l}33 \% \\
(1)\end{array}$ & $\begin{array}{l}0 \% \\
(0)\end{array}$ & $\begin{array}{l}0 \% \\
(0)\end{array}$ & $11 \%(1)$ & - & $\begin{array}{l}0 \% \\
(0)\end{array}$ & $\begin{array}{l}0 \% \\
(0)\end{array}$ \\
\hline Teacher & $33 \%(3)$ & $\begin{array}{l}33 \% \\
(3)\end{array}$ & $\begin{array}{l}11 \% \\
(1)\end{array}$ & $\begin{array}{l}0 \% \\
(0)\end{array}$ & $17 \%(1)$ & $\begin{array}{l}0 \% \\
(0)\end{array}$ & $\begin{array}{l}33 \% \\
(2)\end{array}$ & $\begin{array}{l}17 \% \\
(1)\end{array}$ & $22 \%(2)$ & - & $\begin{array}{l}0 \% \\
(0)\end{array}$ & $\begin{array}{l}0 \% \\
(0)\end{array}$ \\
\hline Other & $0(0)$ & $\begin{array}{l}0 \% \\
(0)\end{array}$ & $\begin{array}{l}0 \% \\
(0)\end{array}$ & $\begin{array}{l}11 \% \\
(1)\end{array}$ & $17 \%(1)$ & $\begin{array}{l}33 \% \\
(1)\end{array}$ & $\begin{array}{l}0 \% \\
(0)\end{array}$ & $\begin{array}{l}17 \% \\
(1)\end{array}$ & $11 \%(1)$ & - & $\begin{array}{l}50 \% \\
(1)\end{array}$ & $\begin{array}{l}0 \% \\
(0)\end{array}$ \\
\hline $\begin{array}{l}\text { Not sought } \\
\text { help }\end{array}$ & $11 \%(1)$ & $\begin{array}{l}0 \% \\
(0)\end{array}$ & $\begin{array}{l}22 \% \\
(2)\end{array}$ & $\begin{array}{l}44 \% \\
(4)\end{array}$ & $0 \%(0)$ & $\begin{array}{l}33 \% \\
(1)\end{array}$ & $\begin{array}{l}0 \% \\
(0)\end{array}$ & $\begin{array}{l}17 \% \\
(1)\end{array}$ & $33 \%(3)$ & - & $\begin{array}{l}0 \% \\
(0)\end{array}$ & $\begin{array}{l}33 \% \\
(1)\end{array}$ \\
\hline $\begin{array}{l}\text { \% Seeking } \\
\text { Help* }\end{array}$ & $89 \%(8)$ & $\begin{array}{l}100 \% \\
(9)\end{array}$ & $\begin{array}{l}78 \% \\
(7)\end{array}$ & $\begin{array}{l}56 \% \\
(5)\end{array}$ & $\begin{array}{l}100 \% \\
(6)\end{array}$ & $\begin{array}{l}67 \% \\
(2)\end{array}$ & $\begin{array}{l}100 \% \\
(6)\end{array}$ & $\begin{array}{l}83 \% \\
(5)\end{array}$ & $67 \%(6)$ & - & $\begin{array}{l}100 \% \\
(5)\end{array}$ & $\begin{array}{l}67 \% \\
(2)\end{array}$ \\
\hline
\end{tabular}

*percentages are calculated from total number of participants completing the AHSQ at the respective time point.

Note

numbers in parentheses is the number of individual responses $(n)$.

\section{Post-Intervention Changes to Mental Health Status}

As outlined previously, the primary aim of pilot studies is to assess their feasibility and acceptability [55]. As with help-seeking, exploratory analysis was conducted to examine any changes to mental health status at follow up. Indeed, these findings should be interpretated tentatively due to small sample sizes and differences in drop-out rates between the interventions. Intervention 1 and 2 did not yield any significant improvement to mental health status at post-, 2-week, or 4-week follow up when compared to baseline (Table 7). Similarly, no significant changes to mental health status were observed in intervention 3 at 2-week or 4-week follow up when compared to baseline (Table 7). 
Table 7

Summary of Means (SD) and test for significance (t-tests) for post-, 2-week, and 4-week follow up change in scores for help-seeking attitudes and mental health status.

\begin{tabular}{|c|c|c|c|c|}
\hline & Mean (SD) & & & \\
\hline Intervention & Baseline & Post & 2-Week Follow Up & 4-Week Follow Up \\
\hline \multicolumn{5}{|c|}{ Help-Seeking Attitudes (ATSPPHS-SF) } \\
\hline Intervention 1 (Men-Tality) & $21.44(4.25)$ & $22.11(3.95)$ & $21.11(4.17)$ & $22.44(3.81)$ \\
\hline Intervention 2 (Psych Strength) & $19.00(3.29)$ & $19.33(5.69)$ & $20.83(4.62)$ & $20.67(5.20)$ \\
\hline Intervention 3 (Man Cave) & $14.22(5.29)$ & - & $20.00(8.49)$ & $14.67(12.66)$ \\
\hline \multicolumn{5}{|l|}{ Mental Health Status (WEMWBS) } \\
\hline Intervention 1 (Men-Tality) & $50.44(7.68)$ & $49.67(7.78)$ & $48.67(7.86)$ & $49.89(9.78)$ \\
\hline Intervention 2 (Psych Strength) & $43.00(13.31)$ & $32.67(7.37)$ & $44.67(8.19)$ & $44.33(9.35)$ \\
\hline Intervention 3 (Man Cave) & 46.89 (13.07) & - & $46.00(22.63)$ & $53.67(12.90)$ \\
\hline$* p<0.05$ & & & & \\
\hline
\end{tabular}

All comparisons are made with Baseline as the reference group.

\section{Discussion}

All three interventions were rated positively regarding their overall acceptability, affective attitude, ethicality, self-efficacy, intervention coherence for help-seeking, and perceived effectiveness for help-seeking and well-being (aim 1). All interventions were rated equally acceptable (aim 2), indicating that the BCTs embedded across these interventions are acceptable strategies to engage male students. Regarding our third aim, only intervention 3 (Man Cave) was significantly better at engaging male students; as they were less likely to have sought help before, held more negative help-seeking attitudes, and who endorsed self-stigmatising beliefs and conformity to masculine norms similar to that of male student norms. Intervention 1 (Men-Tality) was significantly better at engaging male students who endorsed less self-stigmatising beliefs, less conformity to masculine norms (particularly heterosexual self-preservation and power over women), and more positive help-seeking attitudes than expected for this population group. Intervention 2 (Psychological Strength) was also significantly better at engaging male students who endorsed less self-stigmatising beliefs compared to male student norms. Students attending intervention 2 exhibited similar help-seeking attitudes as expected for this population group, however appeared to score significantly higher for the masculine trait of winning, and lower for heterosexual selfpreservation.

Self-stigma was only lower for interventions 1 and 2 when compared to male student norms suggesting that intervention 3 engaged a more representative sample of male students with high self-stigma. The majority of participants attending intervention 3 had not previously sought help for mental health difficulties which may be due to higher self-stigma. This is an important consideration when designing future male-sensitive interventions, as self-stigma is a key barrier to engaging with mental health support [16, 17]. Informal approaches are likely to be more acceptable to male students with high self-stigma, particularly if they have not engaged with mental health support previously.

Participants attending interventions 1 and 2 had significantly lower total conformity to masculine norms, power over women, and heterosexual self-preservation than expected for this population group. Indeed, these maladaptive masculine traits are barriers to help-seeking as total conformity to masculine norms negatively influence help-seeking attitudes $[14,15,19,20]$, power over women contributes to worse mental health outcomes [24], and greater heterosexual self-preservation can be seen as a dimension of antifemininity contributing to greater help-seeking reluctance [21]. Additionally, winning was significantly higher for participants in intervention 2 which can be considered as an adaptive trait as it has been shown to encourage help-seeking and act as a protective factor from mental health difficulties [25]. These findings indicate that those attending interventions 1 and 2 probably represent an atypical subgroup of male students who may be more amenable to therapy as they experience less barriers (and more facilitators) when seeking help for mental health. This was not observed for intervention 3 as no significant differences to conformity to 
masculine norms was identified when compared to male student norms. The informal approaches and strategies seen in intervention 3 appeared to be more acceptable at engaging male students whose conformity to masculine norms are representative of the wider male student population.

Similarly, interventions 1 and 2 had higher help-seeking attitudes at baseline indicating that these students already held positive attitudes to help-seeking. Previous studies highlight that students who recently used mental health support score higher on the ATSPHH-SF compared to those who do not [47]. Significantly more negative help-seeking attitudes were seen in intervention 3 at baseline. These participants scored lower than what was expected for this population group, presenting with similar scores for those who do not use mental health support [47]. Additionally, participants in intervention 3 were significantly less likely to have accessed mental health support in the past when compared to participants in interventions 1 and 2. Once again, although this study was small, these findings indicate that the informal drop-in intervention (intervention 3; Man Cave), appeared to be better at engaging male students who are likely to be representative of the wider male student population where they hold negative help-seeking attitudes and are less likely to have engaged with mental health support before.

For all three interventions, no significant changes to mental health status were observed at post-intervention, 2-week, or 4-week follow up when compared to baseline, possibly due to small sample sizes and loss of follow-up data. However, mental health status at baseline did not differ from male student norms. Across all three interventions, only 5 participants $(20 \%)$ scored equal to or below 40 on the WEMWBS at baseline which can be used to indicate major depression [56]. Therefore, the majority of participants would not fulfil diagnostic criteria for depression and no significant changes to mental health status are likely to be due to a ceiling effect. Participants who scored equal to or below 40 on the WEMWBS were equally distributed across the three interventions, with one participant in intervention 1, two participants in interventions 2 and 3.

Similarly, no significant changes to help-seeking attitudes or behaviours at post-intervention, 2-week, or 4-week follow up were observed. No significant changes to help-seeking attitudes or mental health outcomes at follow-up were observed (aim 4), although such findings may be difficult to interpret due to small sample sizes and limited follow-up data.

Certainly, these pilot interventions are likely to be underpowered to detect any significant changes and such findings should be interpreted tentatively. Instead, more attention should be given to their acceptability.

Overall, the three interventions engaged different subgroups of male students. Interventions 1 and 2 engaged male students who held pre-existing positive help-seeking attitudes, had lower self-stigma, who are more likely to have engaged with mental health support previously, and had lower conformity to maladaptive masculine traits. Intervention 3 appeared better at engaging male students who had higher conformity to maladaptive masculine traits, higher self-stigma, negative perceptions of help-seeking, and who were less likely to have come in to contact with mental health services before. As self-stigma, conformity to masculine norms, and negative help-seeking attitudes have been highlighted as key barriers to engaging with mental health support $[15,17,19,20]$, participants engaging with intervention 3 are likely to be representative of the wider male student cohort who are a hard-to-reach group. Similarly, participants attending intervention 3 were more likely to be from an ethnic minority background which is also associated with reduced help-seeking behaviours for mental health difficulties [57-59]. There may be cause for concern for this hard-to-reach group if they were to experience emotional distress at a later date. Having more barriers to navigate through may reduce their willingness to engage with support when needed. This is likely to reduce their opportunity for support, place them at greater risk of emotional distress, and potentially suicide.

Considering all three interventions were rated equally acceptable, a one-size fits all approach to engage male students is not recommended. As both the formal and informal interventions were deemed equally acceptable, both these strategies may be required within a university setting to engage different types of male students. Informal drop-in interventions may or may not improve mental health outcomes, but instead may help engage hard-to-reach male students, provide a point of contact, and triage them to appropriate mental health support if needed. Certainly, informal spaces can assist with building rapport, trust, and familiarity with support which are often associated with future help-seeking $[32,33,60]$.

Student mental health research tends to ignore gender and sex differences [61,62]. Such investigations do not position themselves to be gender-sensitive and instead adopt a gender-neutral approach to mental health research. Due to this, it is likely that the male students who do take part are not representative of the wider male student population who are hard-to-reach [61, 62]. Gender-neutral approaches may undermine the validity and efficiency of scientific findings, resulting in the inappropriate application of findings

Page $16 / 23$ 
contributing to a detrimental impact for both male and female students [61]. Future research is required to explore the overall effectiveness and acceptability of informal interventions such as drop-ins, social spaces, or student workshops for male students that are not primarily focused on mental health and well-being.

\section{Strengths \& Limitations}

A strength of this investigation is that the components identified from our systematic review and qualitative work consisting of: delivering mental health information, explaining how to identify mental health symptoms, incorporating active-problem solving techniques to cope with distress, sign-posting mental health services, re-framing help-seeking to align with masculine values, avoiding labels of mental health; and to use both formal and informal approaches were acceptable for male students $[11,29,30]$. Furthermore, this paper provides a detailed description of the intervention's active ingredients through the use of BCTs to enable healthcare and education providers to replicate, implement, and refine the proposed interventions.

By obtaining scores for self-stigma, previous mental health support, and conformity to masculine norms a richer picture of the types of male students who did engage is provided. This enhances the clinical applications of the current findings and provides more constructive evidence as to how to engage male students who are often hard to reach and potentially at greater risk of mental health. This is also a different approach than that traditionally used in mental health services, but may be more similar to the informal method used in the men's sheds movement $[63,64]$.

Despite this, there are limitations. Although a sample size of 24 was obtained, this was split across three different interventions with smaller sample sizes. It is likely that these are underpowered to detect any significant changes $[65,66]$. Nonetheless, pilot interventions remain essential as they are informative about the research process and can indicate likely outcomes [67]. Instead, pilot studies are the best way to assess feasibility and attention should be given to the descriptive nature of each sample and the acceptability of the interventions [55].

Intervention 3 was an informal drop-in whereby students could attend without pre-registering, came in and out as they pleased, and attend as few sessions as they liked. As this was a formal investigation, informed consent and the completion of questionnaires was still required. This discouraged certain students from attending and was a barrier for 6 students who opted against consenting to take part. Of those who did consent, reassurance surrounding confidentiality and anonymity of the data collected was required. Indeed, this may align with this hard-to-reach group as they may be less familiar with mental health support - including research, less trusting of mental health professionals, and more fearful of how they will be perceived (i.e. stigma) [36]. This is important to consider, as research processes can be a barrier when evaluating and engaging male students with mental health initiatives.

Due to logistical difficulties and to prevent cross-contamination between the interventions, it was not possible to pilot all three interventions at the same time. This led to different recruitment approaches, with intervention 1 making use of the welcome fair at the start of the academic year when students have more time available and motivation to engage [29]. Intervention 2 was delivered after the Christmas/winter-break. Students at this stage have different time resources available. They may have more time due to feeling more settled with their academic studies, or less time due to coursework, exams, and other deadlines. Similarly, greater emotional stress related to coursework and exam pressure may be present, this may encourage them to access support or reduce their availability to seek help [29]. Intervention 3 was delivered towards the end of the term (as opposed to the start as seen in interventions 1 and 2), causing other restrictions. The fourth week of delivering the drop-in coincided with student reading week - where students course content is solely delivered online and via textbooks. This meant there were less students utilising the café and reduced the opportunity for students to engage. These differences may have impacted the sample of students engaging, acceptability scores, and uptake.

\section{Conclusions}

The current investigation provides insight into different strategies and approaches to designing gender-sensitive mental health interventions for male students. Although formal and structured mental health interventions that provide mental health information alongside self-help techniques and skills are acceptable to male students, more informal approaches such as drop-ins or social spaces are equally acceptable. Furthermore, these informal approaches may be more acceptable and have better uptake for hard-toreach male students who hold stigmatising beliefs, conform to maladaptive masculine traits, have pre-existing negative help-seeking attitudes, are of ethnic minority backgrounds, and who are less likely to have come in to contact with mental health services in the

Page 17/23 
past - which is more representative of the male student cohort. Indeed, informal interventions may provide better uptake of male students and improve their engagement. Such approaches will help to facilitate help-seeking behaviours, increasing the opportunity

to combat mental health difficulties, and possibly reduce the risk of suicide. Moving forward, fully powered future research examining the effectiveness and acceptability of informal mental health initiatives and how best to tailor them to male students is required as this remains a relatively unexplored therapeutic opportunity that has a lot of promise.

\section{Abbreviations}

\begin{tabular}{|ll|}
\hline AHSQ & Actual Help-Seeking Questionnaire \\
\hline ATSPPHS-SF & Attitudes Towards Seeking Psychological Help-Scale \\
\hline BCT & Behaviour Change Technique \\
\hline BCTTV1 & Behavioural Change Technique Taxonomy \\
\hline CBT & Cognitive Behavioural Therapy \\
\hline CMNI-46 & Conformity to Masculine Norms Inventory \\
\hline CONSORT & Consolidated Standards for Reporting Trials \\
\hline IOPPN & Institute of Psychiatry, Psychology and Neuroscience \\
\hline NIHR & National Institute for Health Research \\
\hline SSOSH & Self Stigma of Seeking-Help Scale \\
\hline TFAQ & Theoretical Framework of Acceptability Questionnaire \\
\hline TIDieR & Template for Intervention Description and Replication \\
\hline WEMWBS & Warwick-Edinburgh Mental Well-Being Scale \\
\hline
\end{tabular}

\section{Declarations}

Ethics approval and consent to participate

Ethical approval was granted by the Psychiatry, Nursing and Midwifery Research Ethics Committee from King's College London, reference numbers LRS-18/19-13460, RESCM-19/20-13460, and LRS-19/20-14632. Informed written consent was sought and obtained from all participants. All the research methods within this manuscript were performed in accordance with the BMC guidelines and regulations.

\section{Consent for publication}

Data that is included within the manuscript is anonymised and does not identify participants. All participants signed and completed a consent form stating, "the information I have submitted will be anonymised as a part of a PhD thesis, conference presentation and a publishable report".

\section{Availability of data and materials}

The datasets generated and/or analysed during the current study are not publicly available due to this being an independent pilot study as part of a PhD project, but are available from the corresponding author on reasonable request.

\section{Competing interests}

The current study does not have any competing interests.

Funding 
This paper represents independent research funded by the National Institute for Health Research (NIHR) Biomedical Research Centre at South London and Maudsley NHS Foundation Trust and King's College London. The views expressed are those of the author(s) and not necessarily those of the NHS, the NIHR or the Department of Health and Social Care.

\section{Authors' contributions}

Ilyas Sagar-Ouriaghli, NIHR Maudsley BRC PhD Student, MSc, BSc, NIHR Maudsley BRC PhD Student. Department of Psychology, Institute of Psychiatry, Psychology \& Neuroscience, King's College London, United Kingdom. Contributions include: formulating the research question, developing and designing the interventions, completing the ethics application, recruitment of participants, delivering the interventions, analysis and collection of data, and writing of the report.

June S.L Brown, PhD, MPsychol (Clin), BSc, Senior Lecturer in Clinical Psychology

Department of Psychology, Institute of Psychiatry, Psychology \& Neuroscience, King's College London, United Kingdom. Contributions include: formulating the research questions, developing and designing the interventions, assisting in interpreting data collected, advice about mental health help-seeking and access to care by men, and assisting with the write up of paper.

Vinay Tailor, Medical Student, GKT School of Medical Education, King's College London, London, United Kingdom. Contributions include: assisting with recruitment, co-facilitation and delivery of interventions, collecting data, and reviewing the finalised report.

Emma Godfrey PhD, Senior Lecturer in Health Psychology, Department of Psychology, Institute of Psychiatry, Psychology \& Neuroscience, King's College London, London, United Kingdom. Contributions include: formulating the research question, providing supervision of the development and design of the interventions, guidance on conducting and interpreting feasibility studies, and assisting with the write up of the report.

\section{References}

1. O'Neil S, Auerbach RP, Alonso J, Axinn WG, Cuijpers P, Ebert DD, Green JG, Hwang I, Kessler RC, Liu H, Mortier P, Nock MK, PinderAmaker S, Sampson NA, Aguilar-Gaxiola S. Mental disorders among college students in the WHO World Mental Health Surveys. Psychol Med. 2016;46(14):2955-70.

2. McManus S, Gunnell D. Trends in mental health, non-suicidal self-harm and suicide attempts in 16-24 year old students and nonstudents in England, 2000-2014. Soc Psychiatry Psychiatr Epidemiol. 2020;55(1):125-8.

3. Bruffaerts R, Mortier P, Kiekens G, Auerbach RP, Cuijpers P, Demyttenaere K, Green JG, Nock MK, Kessler RC. Mental health problems in college freshmen: Prevalence and academic functioning. J Affect Disord. 2018;225:97-103.

4. Eisenberg D, Golberstein E, Gollust SE. Help-Seeking and Access to Mental Health Care in a Univeristy Student Population. Med Care. 2007;45:594-601.

5. Hjorth CF, Bilgrav L, Frandsen LS, Overgaard C, Torp-Pedersen C, Nielsen B, Bøggild H. Mental health and school dropout across educational levels and genders: a 4.8-year follow-up study. BMC Public Health. 2016;16:976

6. Liu CH, Stevens C, Wong SH, Yasui M, Chen JA. The prevelance and predictors of mental health diagnoses and suicide among US college students: Implications for addressing disparities in service use. Depress Anxiety. 2019;36(1):8-17.

7. Gunnell D, Caul S, Appleby L, John A, Hawton K. The incidence of suicide in University students in England and Wales 2000/2001 - 2016/2017: Record linkage study. J Affect Disord. 2020;261:113-20.

8. Chang Q, Yip PS, Chen Y. Gender inequality and suicide gender rations in the world. J Affect Disord. 2019;243:297-304.

9. Cadigan JM, Lee CM, Larimer ME. Young adult mental health: A prospective examination of service utilization, percieved unmet service needs, attitudes, and barriers to service use. Prevention Science. 2019;20(3):366-76.

10. Pedrelli P, Borsari B, Lipson SK, Heinze JE, Eisenberg D. Gender differences in the relationship among major depressive disorder, heavy alcohol use, and mental health treatment engagement among college students. J Stud Alcohol Drugs. 2016;77(4):620-8.

11. Sagar-Ouriaghli I, Godfrey E, Graham S, Brown JS. Improving Mental Health Help-Seeking Behaviours for Male Students: A Framework for Developing a Complex Intervention. Int J Environ Res Public Health. 2020;17(14);4965-90.

12. Nam SK, Chu HJ, Lee MK, Lee HJ, Kim N, Lee SM. A meta-analysis of gender differences in attitudes toward seeking professional psychological help. J Am Coll Health. 2010;59(2):110-16.

Page $19 / 23$ 
13. Clough BA, Nazareth SM, Day JJ, Casey LM. A comparison of mental health literacy, attitudes, and help-seeking intentions among domestic and international teritary students. Br J Guid Counc. 2019;47(1):123-35.

14. Seidler ZE, Dawes AJ, Rice SM, Oliffe JL, Dhillon HM. The role of masculinity in men's help-seeking for depression: a systematic review. Clin Psychol Rev. 2016;49:106-18.

15. Ramaeker J, Petrie TA. "Man up!": Exploring intersections of sport participation, masculinity, psychological distress, and helpseeking attitudes and intentions. Psychol Men Masc. 2019;20(4):515-27.

16. Wu IH, Bathje GJ, Kalibatseva Z, Sung D, Leong FT, Collins-Eaglin J. Stigma, mental health, and counseling service use: A personcentred approach to mental health stigma profiles. Psychol Serv. 2017;14(4):490-501.

17. Levant $K$, Kamaradova D, Prasko J. Perspectives on percieved stigma and self-stigma in adult male patients with depression. Neuropsychiatr Dis Treat. 2014;10:1399.

18. Haavik L, Joa I, Hatloy K, Stain HJ, Langeveld J. Help seeking for mental health problems in an adolescent population: the effect of gender. J Ment Health. 2017;28(5):467-74.

19. Vogel DL, Heimerdinger-Edwards SR, Hammer JH and Hubbard A. "Boys don't cry": Examination of the links between endorsement of masculine norms, self-stigma and help-seeking attitudes. J Couns Psychol. 2011;58:368-82.

20. Wimer DJ, Levant RF. The relation of masculinity and help-seeking style with the academic help-seeking behavior of college men. J Mens Stud. 2011;19(3):256-74.

21. Sileo KM, Kershaw TS. Dimensions of Masculine Norms, Depression, and Mental Health Service Utilization: Results From a Prospective Cohort Study Among Emerging Adult Men in the United States. Am J Mens Health. 2020;14(1):1-16.

22. Heath PJ, Brenner RE, Vogel DL, Lannin DG, Strass HA. Masculinity and barriers to seeking counselling: The buffering role of selfcompassion. J Couns Psychol. 2017;64(1):94-103.

23. Gorski E. Stoic, stubborn, or sensitive: How masculinity affects men's help-seeking and help-referring behaviors. UW-L Journal of Undergraduate Research. 2010;13:1-6.

24. Wong YJ, Ho MR, Wang SY, Miller IS. Meta-analyses of the relationship between conformity to masculine norms and mental health-related outcomes. J Couns Psychol. 2017;64(1):80-93.

25. Iwamoto DK, Brady J, Kaya A, Park A. Masculinity and depression: a longitudinal investigation of multidimensional masculine norms among college men. Am J Mens Health. 2018;12(6):1873-81.

26. Ratnayake P, Hyde C. Mental Health Literacy, Help-Seeking Behaviour and Wellbeing in Young People: Implications for Practice. The Educational and Development Psychologist. 2019;36(1):16-21.

27. Mackenzie CS, Visperas A, Ogrondniczuk JS, Oliffe JL, Nurmi MA. Age and sex differences in self-stigma and public stigma concerning depression and suicide in men. Stigma Health. 2019;4(2):233-41.

28. Schoen E, Brock R, Hannon J. Gender bias, other specified and unspecified feeding and eating disorders, and college students: a vignette study. Eat Disord.,2019;27(3):291-304.

29. Sagar-Ouriaghli I, Brown JS, Vinay T, Godfrey E. Engaging Male Students with Mental Health Support: A Qualitative Focus Group Study. BMC Public Health. 2020;20(1)1-4.

30. Sagar-Ouriaghli I, Godfrey E, Bridge L, Meade L, Brown JS. Improving Mental Health Service Utilization Among Men: A Systematic Review and Synthesis of Behavior Change Techniques Within Interventions Targeting Help-Seeking. Am J Mens Health.

2019;13:1-18.

31. Patrick S, Robertson S. Mental health and wellbeing: focus on men's health. Br J Nurs. 2016;25(21):1163-9.

32. Liddon L, Kingerlee R, Seager M, Barry JA. What are the factors that make a male-friendly therapy?. In Barry JA, Kingerlee R, Seager M, Sullivan L, editors. The Palgrave Handbook of Male Psychology and Mental Health. Cham, Palgrave Macmillan; 2019. P.671-94.

33. Seidler ZE, Rice SM, Ogrodniczuk JZ, Oliffe JL, Dhillon HM. Engaging Men in Psychological Treatment: A Scoping Review. Am J Mens Health. 2018;12:1882-1900.

34. Erentzen C, Quinlan JA, Mar RA. Sometimes you need more than a wingman: Masculinity, femininity, and the role of humor in men's mental health help-seeking campaigns. J Soc Clin Psychol. 2018;37:128-57.

35. American Psychological Association. APA guidelines for psychological practice with boys and men. 2018. http://www.apa.org/about/policy/psychological-practice-boys-men-guidelines.pdf. Acessed 28 Nov 2020.

Page 20/23 
36. Yousaf $\mathrm{O}$, Grunfeld EA, Hunter MS. A systematic review of the factors associated with delays in medical and psychological helpseeking among men. Health Psychol Rev. 2015;9(2):264-76.

37. Brown JS, Sagar-Ouriaghli I, Sullivan L. Help-seeking among men for mental health problems. In The Palgrave Handbook of Male Psychology and Mental Health, Cham, Palgrave Macmillan. 2019:397-415.

38. Sekhon M, Cartwright M, Francis JJ. Development of a theory-informed questionnaire to assess the acceptability of healthcare interventions: application of pre-validation methods. In UK Society of Behavioural Medicine, Birmingham, 2018.

39. Sekhon M, Cartwright M, Francis JJ. Acceptability of healthcare interventions: an overview of reviews and development of a theoretical framework. BMC Health Serv Res. 2017;17(1):1-3.

40. Mahalik JR. Locke BD, Ludlow L, Diemer MA. Development of the Conformity to Masculine Norms Inventory. Psychol Men Masc. 2003;4(1):3-25.

41. Vogel DL, Wade NG, Hackler AH. Percieved public stigma and the willingness to seek counseling: The mediating roles of selfstigma and attitudes toward counseling. J Couns Psychol. 2007;54:40-50.

42. O'Brein R, Hunt, K, Hart G. 'It's caveman stuff, but that is to a certain extent how guys still operate': men's accounts of masculinity and help seeking. Social science \& medicine. 2005;61(3):503-16.

43. Parent MC, Moradi B. An Abbreviated Tool for Assessing Conformity to Masculine Norms: Psychometric Properties of the Conformity to Masculine Norms Inventory-46. Psychol Men Masc. 2011;12(4):339-53.

44. Fischer EH, Farina A. Attitudes toward seeking professional psychological help: A shortened form and considerations for research. J Coll Stud Dev. 1995;36(4):368-73.

45. Wilson CJ, Deane FP, Ciarrochi JV, Rickwood D. Measuring help seeking intentions: properties of the general help seeking questionnaire. Canadian Journal of Counselling. 2005;39(1):15-28.

46. Rickwood, Deane FP, Wilson CJ, Ciarrochi, JV. Young people's help-seeking for mental health problems. Australian e-journal for the Advancement of Mental Health. 2005;4:218-51.

47. Elahi JD, Schweinle W, Anderson SM. Reliabilty and validity of the Attitudes Toward Seeking Professional Psychological Help Scale-Short Form. Psych Res. 2008;159(3):320-9.

48. Tennant R, Hiller L, Fishwick R, Platt S, Joseph S, Weich S, Parkinson J, Secker J, Stewart-Brown S. The Warwick-Edinburgh mental well-being scale (WEMWBS): development and UK validation. Health Qual Life Outcomes. 2007;5(1):63.

49. Michie S, Johnston M, Carey R. Behaviour change techniques. In Encyclopedia of Behavioral Medicine, New York, Springer. 2016:1-8.

50. Michie S, West R, Sheals K, Godinho CA. Evaluating the effectiveness of behavior change techniques in health-related behavior: a scoping review of methods used. Transl Behav Med. 2018;8(2):212-24.

51. Michie S, Richardson M, Johnston M, Abraham C, Francis J, Hardeman W, Eccles MP, Cane J, Wood CE. The behavior change technique taxonomy $(\mathrm{v} 1)$ of 93 hierarchically clustered techniques: building an international consensus for the reporting of behavior change interventions. Ann Behav Med. 2013;46(1):81-95.

52. Hoffman TC, Glasziou PP, Boutron I, Milne R, Perera R, Moher D, Altman DG, Barbour V, Macdonald H, Johnston M, Lamb SE, Dixon-Woods M, McCulloch P, Wyatt JC, Chan A-W, Michie S. Better reporting of interventions: template for intervention description and replication (TIDieR) checklist and guide. BMJ. 2014;348.

53. Eldridge SM, Chan CL, Campbell MJ, Bond CM, Hopewell S, Thabane L, Lancaster GA. CONSORT 2010 statement: extension to randomised pilot and feasibility trials. BMJ. 2016;355:i5239.

54. Lancaster GA, Thabane L. Guidelines for reporting non-randomised pilot and feasibilty trials. Pilot Feasibility Stud. 2019;5(114):1-6.

55. Thabane L, Ma J, Chu R, Cheng J, Ismaila A, Rios LP, Robson R, Thabane M, Giangregorio L, Goldsmith CH. A tutorial on pilot studies: the what, why and how. BMC Med Res Methodol. 2010;10(1):1-10.

56. Taggart F, Stewart-Brown S, Parkinson J. Warwick-Edinburgh Mental Well-being Scale (WEMWBS) User Guide - Version 2. NHS Health Scotland, Edinburgh. 2015.

57. Parent M, Hammer JH, Bradstreet TC, Schwartz EN, Jobe T. Men's Mental Health Help-Seeking Behaviors: An Intersectional Analysis. Am J Mens Health. 2018;12(1):64-73. 
58. Twentyman J, Frank M. Effects of Race and Ethnicitiy on Mental Health and Help-Seeking amongst Undergraduate University Students. Journal of Undergraduate Ethnic Minority Psychology. 2017;3(6):2332-9300.

59. Guo S, Nguyen H, Weiss B, Ngo V, Lau AS. Linkages between mental health need and help-seeking behavior among adolescents: Moderating role of ethnicity and cultural values. J Cous Psychol. 2015;62(4):682-93.

60. Gulliver A, Griffiths KM, Christensen H. Percieved barriers and facilitators to mental health help-seeking in young people: a systematic review. BMC Psychiatry. 2010;10:113.

61. Howard LM, Ehrlich AM, Gamlen F, Oram S. Gender-neutral mental health research is sex and gender biased. Lancet Psychiatry. 2017;4(1):9-11.

62. Ryan J, Lopian L, Le B, Edney S, Van Kessel G, Plotnikoff R, Vandelanotte C, Olds T, Maher C. It's not raining men: a mixedmethods study investigating methods of improving male recruitment to health behaviour research. BMC Public Health. 2019;19(1):814-23.

63. Wilson NJ, Cordier R. A narrative review of Men's Sheds literature: reducing social isolation and promoting men's health and wellbeing. Health Soc Care Community. 2013;21(5):451-63.

64. Morgan M, Hayes R, Williamson M, Ford C. Men's Sheds: A Community Approach to Promoting Mental Health and Well-Being.Int J Ment Health Promot. 2007;9(3):48-52.

65. Maxwell SE. The persistence of underpowered studies in psychological research: causes, consequences and remedies. Psychol Methods. 2004;9(2):147.

66. Krzywinski M, Altman N. Points of Significance: Power and Sample Size. Nat Methods. 2013;10(12):1139-40.

67. Van Teijlingen ER, Hundley V. The importance of pilot studies. Social Research UPDATE. 2001:35.

\section{Figures}




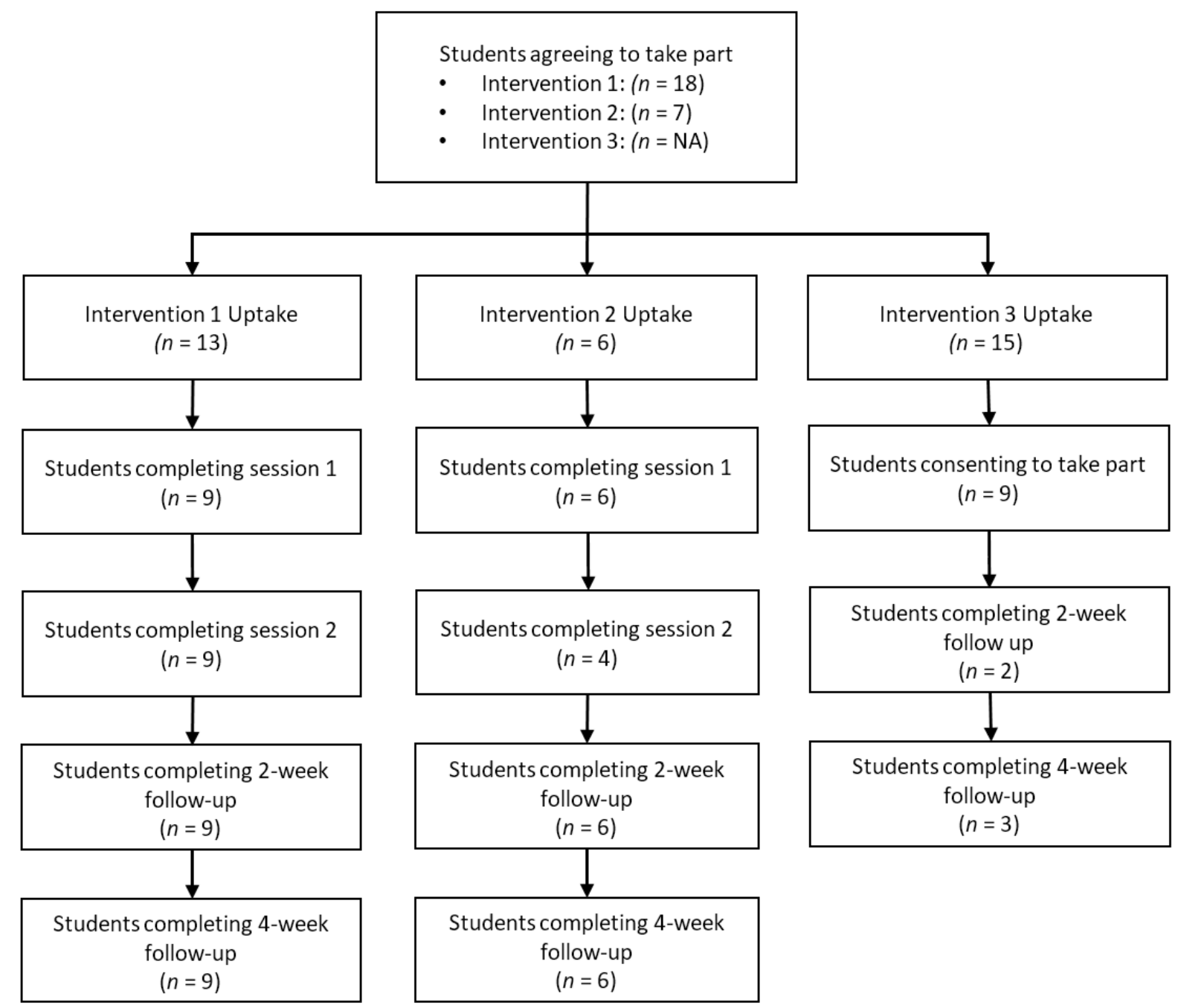

Figure 1

Recruitment flow chart across all three pilot interventions.

\section{Supplementary Files}

This is a list of supplementary files associated with this preprint. Click to download.

- BMCPsychSupplementaryMaterials.docx 